\title{
DISCUSSION
}

\section{Effects of particle breakage and stress reversal on the behaviour of sand around displacement piles}

\author{
FATIN N. ALTUHAFI*, RICHARD J. JARDINE $\dagger$, VASSILIKI N. GEORGIANNOU $\$$, WAY WAY MOINET§, \\ MATTEO ORYEM CIANTIA\|, MARCOS ARROYO $\mid$ and ANTONIO GENS
}

\section{Contribution by Matteo Oryem Ciantia, Marcos Arroyo and Antonio Gens}

Sand gradation and derived properties are modified by pile installation. The authors deserve praise for providing an extensive and unprecedented set of triaxial data to clarify this fundamental issue (Altuhafi et al., 2018). One conclusion of practical significance refers to the position of critical state lines in the compression plane. The authors state that 'New critical state lines apply to the fractured sand that fall substantially below those manifested by fresh samples when sheared at lower effective stress levels'.

The discussion contributors would like to offer here a complementary view, based on recently published results from a discrete-element method (DEM) model of Fontainebleau sand (Ciantia et al., 2018). Muir Wood \& Maeda (2008) introduced the idea of a unique critical state plane (CSP), to which all critical state lines of a given sand at different stages of grading evolution would belong. A CSP equation may be written as

$$
e_{\mathrm{cs}}=\alpha+\beta I_{\mathrm{G}}+\delta\left(\frac{p_{\mathrm{cs}}^{\prime}}{p_{\mathrm{atm}}}\right)^{0 \cdot 7}
$$

where $e_{\mathrm{cs}}$ and $p_{\mathrm{cs}}^{\prime}$ are the values of void ratio and mean effective stress at critical state and $I_{\mathrm{G}}$ is the grading state index (Muir Wood, 2007), quantifying the evolution of grading when critical state is attained. The parameters $\alpha, \beta$ and $\delta$ are to be determined by experiment.

Ciantia et al. (2018) performed an extensive set of numerical high-pressure triaxial tests in which grading evolution was continuously tracked. From that work it followed that the CSP of Fontainebleau sand was given by

$$
e_{\mathrm{cs}}=2.553-2.441 I_{\mathrm{G}}-0.002325\left(\frac{p_{\mathrm{cs}}^{\prime}}{p_{\mathrm{atm}}}\right)^{0.7}
$$

It was shown in Ciantia et al. (2018) that this equation described well the critical states experimentally presented by Luong \& Touati (1983). However, the latter researchers only sheared normally consolidated specimens and not preconsolidated and/or pre-sheared specimens, as the authors have done. It was then with some trepidation that the discussion contributors set out to check if this new set of experimental results would fit the prediction of the numerical model. The results are summarised in Fig. 11 and the

\footnotetext{
* Imperial College, London, UK (Orcid:0000-0003-0035-2586).

$\uparrow$ Imperial College, London, UK (Orcid:0000-0001-7147-5909).

+ National Technical University of Athens, Athens, Greece

(Orcid:0000-0002-9957-8173).

$\S$ Imperial College, London, UK (Orcid:0000-0001-7559-055X).

I| School of Science and Engineering, University of Dundee, UK.

- Department of Civil and Environmental Engineering,

Geosciences Division, UPC, Barcelona, Spain.
}

supporting data are provided in tabulated form as online supplementary material to this discussion. The experiments fit well the numerically predicted CSP, with a normalised standard error of $0 \cdot 1 \%$.

It is perhaps surprising that results derived from such an idealised model as that presented in Ciantia et al. (2018) compare so well with physical experiments. Among its many simplifications, two stand out: non-spherical particle shape effects are mimicked by the expedient approach of blocking element rotations; also some particle volume is lost at every single crushing event. It would appear that it is advantageous to adopt a flexible modelling approach that focuses specifically on the important aspects of granular interaction.

Ciantia et al. (2018) calibrated their DEM model using results from two triaxial tests at low pressure and a single high-pressure oedometer on Fontainebleau sand. That was supplemented with generic single particle crushing information from other quartz sands. The discussion contributors think that the technical skill, human effort and level of investment required to obtain a CSP using DEM simulation is far smaller than that applied by the authors in the laboratory. The discussion contributors wonder if the authors concur with them in believing that the two techniques may share the burden of future efforts in this important research topic.

\section{Authors' reply}

The authors would like to express their appreciation to the discussers for their interest in this work and for extending their DEM modelling to reproduce the CSP that the authors examined in their physical experiments. The authors are aware of the discussers' CSP plane proposals and are highly

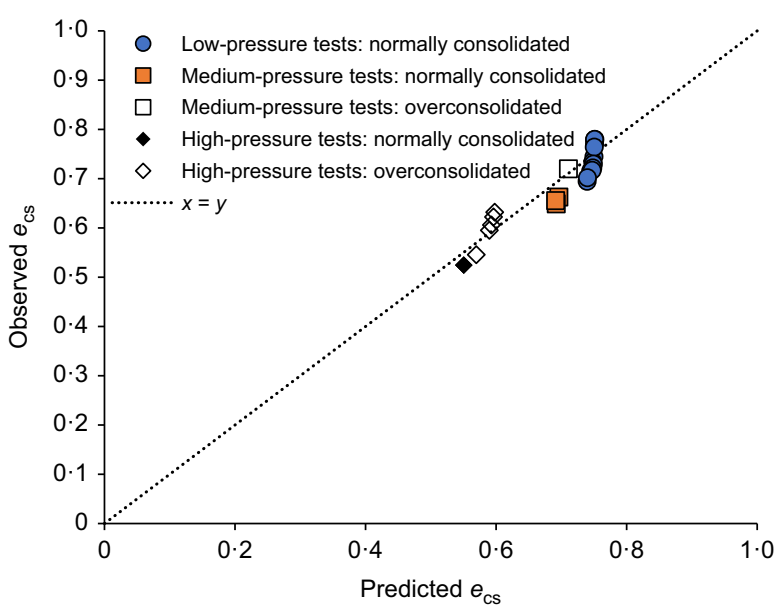

Fig. 11. Comparison of numerically predicted and experimentally obtained critical state data for Fontainebleau sand 
encouraged that the reported DEM simulation outcomes fall so close to the experimental findings. The discussers also refer to particle crushing and changes of soil grading during shearing at high pressures, which raises the question as to whether their simulation was also able to recover the measured changes in soil grading accurately. In addition, were they able to match the experimentally observed dilation rates? The discussers also raise the interesting question of how the non-spherical particle shapes may have led to disparities between their results and the tests. It is interesting that they report that the restrictions they placed on grain rotation in their DEM analysis appear to have made at least partial allowance for the impact of the non-spherical grain shapes of the sand as well as the granular interaction resulting in notable modification to the surface roughness and/or change in particle aspect ratio developed through particle breakage by Fontainebleau sand.

\section{NOTATION}

$e_{\mathrm{cs}} \quad$ void ratio at critical state

$I_{\mathrm{G}} \quad$ grading state index

$p_{\mathrm{cs}}^{\prime}$ mean effective stress at critical state $p_{\text {atm }}$ atmospheric pressure

$\alpha \quad$ experimentally determined parameter

$\beta$ experimentally determined parameter

$\delta$ experimentally determined parameter

\section{REFERENCES}

Altuhafi, F. N., Jardine, R. J., Georgiannou, V. N. \& Moinet, W. W. (2018). Effects of particle breakage and stress reversal on the behaviour of sand around displacement piles. Géotechnique 68, No. 6, 546-555, https://doi.org/10.1680/jgeot. 17.P.117.

Ciantia, M. O., Arroyo, M., O’Sullivan, C., Gens, A. \& Liu, T. (2018). Grading evolution and critical state in a discrete analogue of Fontainebleau sand. Géotechnique 69, No. 1, 1-15, https://doi.org/10.1680/jgeot.17.P.023.

Luong, M. P. \& Touati, A. (1983). Sols grenus sous fortes contraintes. Revue Française de Géotechnique 24, 51-63 (in French).

Muir Wood, D. (2007). The magic of sands - the 20th Bjerrum Lecture presented in Oslo, 25 November 2005. Can. Geotech. J. 44, No. 11, 1329-1350.

Muir Wood, D. \& Maeda, K. (2008). Changing grading of soil: effect on critical states. Acta Geotechnica 3, No. 1, 3-14. 